\title{
The timely expression of coherence helps cause the right impression
}

\author{
Fernando Gordillo ${ }^{1}$ José M. Arana², Juan José G. Meilán², Lilia Mestas³, and Miguel Ángel Pérez \\ ${ }^{1}$ Universidad Camilo José Cela (Spain) \\ ${ }^{2}$ Universidad de Salamanca (Spain) \\ ${ }^{3}$ Facultad de Estudios Superiores Zaragoza (Mexico)
}

\begin{abstract}
Título: Expresar coherencia en el momento preciso beneficia a la impresión causada.

Resumen. Se analizó el papel modulador de la coherencia emocional entre la información verbal y no verbal en la formación de impresiones. Participaron 301 sujetos que realizaron inferencias sobre la personalidad de una mujer a partir de información verbal sobre su vida (positiva, negativa), la coherencia emocional entre la información verbal y no verbal (coherente, neutral, incoherente) y el tipo de codificación, referida al momento en el que se les presentó la información verbal y no verbal (simultánea, separada). Los resultados mostraron que cuando la información es positiva, coherente y la codificación se ha realizado por separado, se considera más estable, amable y sociable a la persona percibida. Se discuten los resultados y su implicación en los procesos adaptativos presentes en los contextos naturales
\end{abstract} Palabras clave: Contexto verbal; emoción; expresión facial
Abstract: An analysis was conducted on the modulating role that the emotional coherence between verbal and non-verbal information plays on the formation of impressions. The study involved 301 subjects who made inferences on a woman's personality based on verbal information on her life (positive, negative), the emotional coherence between verbal and nonverbal information (coherent, neutral, incoherent), and the type of coding, referring to the moment when the verbal and non-verbal information was presented to them (simultaneously, separately). The results showed that when the information is positive, coherent and the coding has been made separately, the person is perceived to be more stable, pleasant and sociable. The results are discussed, along with their implications for the adaptive processes present in natural contexts.

Key words: Verbal context; emotion; facial expression.

\section{Introduction}

The formation of impressions allows combining information on other people that is sometimes incomplete, while generating overall opinions on their cognitive, emotional and behavioural processes, with the aim being to understand, monitor and predict the behaviour of people in our social context (Estrada, Oyarzún, \& Yzerbyt, 2007). This is rendered possible according to implicit theories based on a general understanding of how we think people are (Bruner \& Tagiuri, 1954; Schneider, Hastorf, \& Ellsworth, 1979).

In recent decades, different studies have shown that we are capable of making very accurate judgements on other people's personality, sexual orientation and capabilities based on short, sharp and automatic interactions (Ambady, Bernieri, \& Richeson, 2000; Albright, Kenny, \& Malloy, 1988; Bond, Berry, \& Omar, 1994); even through the simple exposure to static facial expressions (Berry, 1990), where the facial structure plays a decisive role (Hehman, Leitner, Deegan, \& Gaertner, 2013). Furthermore, the presentation of adjectives describing personality (prime) together with a person's picture has a significant impact on the subsequent evaluation of that individual (target) (Bargh, 2006). The formation of impressions may also be affected by more general aspects, such as stereotypes (Ramos, García-Marqués, Hamilton, Ferreira, \& Van Acker, 2012; Sandal, Bye, \& Pallesen, 2012), culture (Lieberman, Jarcho, \& Obayashi, 2005; Krys, Hansen, Xing, Szarota, \& Yang, 2013), and emotions (Hareli \& Weiner, 2002).

The inferences we make on other people stem from social relations, where the verbal information (what we know

* Correspondence address [Dirección para correspondencia]: Fernando Gordillo León. Universidad Camilo José Cela. Facultad de Salud. Departamento de Psicología. C/ Castillo de Alarcón no 49, 28692, Villafranca del Castillo, Madrid (Spain).E-mail: fgordillo@ucjc.edu about their lives) and non-verbal information (the emotion they express) surrounding them are continuously interacting (see Scherer, Scherer, Hall, \& Rosenthal, 1977). This interaction is modulated by different variables, such as the coherence between verbal and non-verbal information, which have facilitating effects on emotional recognition in three-monthold babies (see Walker-Andrews, 2008). Likewise, and in adults, those emotions that are clearly recognised through a communication channel (e.g., the face) become difficult to interpret when another channel is included with incoherent information (e.g., the body) (Aviezer et al., 2008; Van den Stock et al., 2008). Regarding the formation of impressions, the coherence between verbal and non-verbal information improves the impression gained on the friendliness of the person evaluated (Weisbuch, Ambady, Clarke, \& Achor, 2010), while incoherence leads to impressions of falseness (Argyle, Alkema, \& Gilmour, 1971; Heinrich \& Borkenau, 1998). What's more, negotiation has proven to be important and beneficial in both cases (Kulik, Olekalns, \& Swain, 2014), as has psychotherapy, where the simultaneous and coherent use of verbal and non-verbal confirmation signals has helped to improve the perception of the alliance and empathy between therapist and patient (Battles \& Berman, 2012). Generally speaking, it may be posited that people who are coherent generate positive impressions, and those that are incoherent cause negative impressions (Weisbuch et al., 2010).

Another variable to be taken into account is the moment when the verbal and non-verbal information on an individual is coded. If that information is coded at the same time and prior to inferences being made on their personality, this might lead to a process whereby the non-verbal content interferes with the coding of verbal information, thereby reducing or annulling the joint effect on the inference made. This becomes even more evident regarding an emotional fa- 
cial expression, given its major ability to capture emotional processes, and which has been amply verified in different types of tasks (e.g., Fenske \& Eastwood, 2003; Fox, Russo, Bowles, \& Dutton, 2001; Lamy, Amunts, \& Bar-Haim, 2008; Mogg \& Bradley, 1999; Ohman, Lundqvist, \& Esteves, 2001; Stein, Zwickel, Ritter, Kitzmantel, \& Schneider, 2009). Even when the emotional facial expression is irrelevant to the task being performed, its analysis will require attentional resources that will weaken those applied to the main task (Hodsoll, Viding, \& Lavie, 2011). Finally, account should also be taken of the perceiver's affective state arising from the information supplied, insofar as it impacts upon psychological processes such as attention (see Reeck, 2015), perception (Niedenthal \& Setterlund, 1994), memory (see LaBar \& Cabeza, 2006) and decision-making (see Lerner, Li, Valdesolo, \& Kassam, 2015), which would be capable of the uncontrolled modulation of the effects on the formation of impressions.

The aim of this research, therefore, was to analyse variables that affect the formation of impressions, and which to date have not been addressed jointly or regarding such specific and relevant aspects in the social sphere as personality traits (emotional stability, friendliness, responsibility, sociability and creativity). Accordingly, and based on the theoretical analysis conducted, account was taken of the type of verbal information (positive, negative), the coherence between verbal and non-verbal information (coherent, neutral, incoherent) and the type of coding (simultaneous, separate). Coherence and incoherence are expected to have a beneficial and compromising effect, respectively, on the formation of impressions regarding personality solely when verbal and non-verbal information are coded separately.

\section{Method}

\section{Participants}

The sample consisted of 301 students from Salamanca University (Spain) $\left(M_{\text {age }}=18.93, S D_{\text {age }}=2.53,82.4 \%\right.$ females), who provided their informed consent when they volunteered to take part in the experiment. There were no age differences between the groups regarding the Type of Verbal Information (Tiv) $[t(299)=.111, p=.912]$; Coherence $(\mathrm{Coh})[F(2,298)=1.042, p=.354]$ and Type of Coding $(\mathrm{Tc})$ $[t(299)=1.077, p=.282]$.

\section{Instruments}

The experiment was conducted online through the Socialsci platform (https://research.socialsci.com/). All the subjects were issued with instructions during class-time on the environmental conditions required for undertaking the experiment. Use was made of five words with a positive valence (family, excitement, adventure, sex, and optimism) and five with a negative one (abuse, poverty, horror, nightmare, and depression), taken from the normative study by Redon- do, Fraga, Comesaña, and Perea (2005). They were all similar in terms of their levels of arousal.

Use was also made of two prototypical facial expressions made by the same woman, one of happiness and one of sadness obtained from the NimStim Face Stimulus Set database (Tottenham et al., 2009), to produce three expressions through morphing (25\% happiness-75\% sadness; 50\% happiness-50\% sadness; $75 \%$ happiness- $25 \%$ sadness), based on a combination of the two prototypical expressions and using FantaMorph software (Abrosoft, 2010). Thanks to their greater ambiguity, expressions of this kind enhance the task's sensitivity (Wieser \& Brosch, 2012; Matsumoto \& Hwang, 2010).

The measurement of personality involved the creation of five scales based on the dimensions of the "Big Five" model (NEO-FFI; Costa \& McCrae, 1985). This model is informed by an analysis of the attributes that, in everyday language, describe individual differences (see Costa \& McCrae, 1992), being, therefore, the most suitable approach to studying the natural perception of personality in social contexts.

\section{Procedure}

All the subjects passed through the following stages (for an example of the procedure, see https://research.socialsci.com/s/example): Stage I: They were shown a photo of a woman's face with a mixed expression that could be sad (25\% happiness $/ 75 \%$ sadness), neutral (50\% happiness $/ 50 \%$ sadness) or happy (75\% happiness $/ 25 \%$ sadness) within a circle in which five positive or negative words were distributed. They were told that the words described that person's life and that they had to look at the picture for 60 seconds. They then had to rate the extent to which they considered that the life described by the words was negative or positive (very negative_1..... 9_very positive). Stage II: The mixed facial expression was shown, which could be sad, neutral or happy, without any words, and accompanied by the following statement: In general, I think the woman in the photo is: EMOTIONALLY STABLE: Completely disagree_1.....9_Completely agree; FRIENDLY: Completely disagree_1.....9_Completely agree; RESPONSIBLE: Completely disagree_1.....9_Completely agree; SOCIABLE:Completely disagree_1.....9_Completely agree; CREATIVE: Completely disagree_1.....9_Completely agree. The different personality dimensions evaluated are randomly chosen and shown separately alongside the photo.

\section{Design and data analysis}

Independent variables: 1. Type of Verbal Information (Tvi: positive, negative): this was established using words with a positive and negative emotional content referring to the life of the woman whose personality was to be assessed and which surrounded the facial expression, so when taken as a whole they presented an overview of the life of the person appearing in the photo. 2. Type of Coding (Tc: Simultaneous, separate): this was established by considering the moment when the facial ex- 
pression of happiness or sadness was presented, either when the verbal information was coded (Simultaneous), or subsequently, during the assessment of the personality (separate). A neutral expression always appeared whenever an expression of happiness or sadness was not shown. 3. Coherence between verbal and non-verbal information (Coh: coherent, neutral, incoberent). Coherent meant that the positive and negative Tvi was linked to a facial expression of happiness and sadness, respectively. The opposite was considered to be incoherent. Neutral applied when the positive or negative Tvi was linked to a neutral facial expression.

Controlled variables: Affective evaluation: this variable was measured in Stage I on a scale of 1 to 9, whereby the subjects had to rate the extent to which they thought that person's life was positive or negative. This measure was required to provide information on the degree to which the words' emotional content and the facial expression used to set the levels of the independent variables could generate an affective state that would to some extent modulate the effects found.

Dependent variables: Personality assessment. The measurements were taken through five scales: emotional stability, friendliness, responsibility, sociability and creativity. The scores ranged between one and nine.
Based on the different levels of the independent variables, twelve groups were formed for comparative purposes (table 1). A between-subjects 2 (Tvi) x 2 (Tc) x 3 (Coh) ANOVA was performed with the factors Tvi (positive, negative), Tc (simultaneous, separate) and Coh (coherent, neutral, incoherent) as independent variables, and with affective evaluation and personality assessment (emotional stability, friendliness, responsibility, sociability and creativity) as dependent variables.

\section{Results}

Affective evaluation. The analyses showed a significant effect of Tvi $\left(F_{(1,289)}=988.89, p<.001, \eta^{2}=.77, p=1.00\right)$. The differences favoured a positive Tvi $(M=6.99, S D=$ $1.40)$ over a negative one $(M=2.01, S D=1.35)$. The analyses did not show a significant effect of $\operatorname{Coh}\left(F_{(2,289)}=1.23\right.$, $\left.p=.294, \eta^{2}=.01, p=.27\right)$, or of $\operatorname{Tc}\left(F_{(1,288)}=1.22, p=.270\right.$, $\left.\eta^{2}=.00, \mathrm{P}=.20\right)$ in the affective evaluation. Neither was the interaction effect statistically significant between Tvi and Coh $\left(F_{(2,289)}=1.72, p=.181, \eta^{2}=.01, p=.36\right)$, or between Tvi and Tc $\left(F_{(2,288)}=.67, p=.416, \eta^{2}=.00, p=.13\right)$, Coh and $\operatorname{Tc}\left(F_{(2,289)}=.32, p=.730, \eta^{2}=.00, p=.10\right)$, or between Tvi, Tc and $\operatorname{Coh}\left(F_{(2,289)}=2.56, p=.079, \eta^{2}=.02, p=.51\right)$.

Table 1. Descriptive statistics obtained in the different levels of the independent variables for each one of the dependent variables.

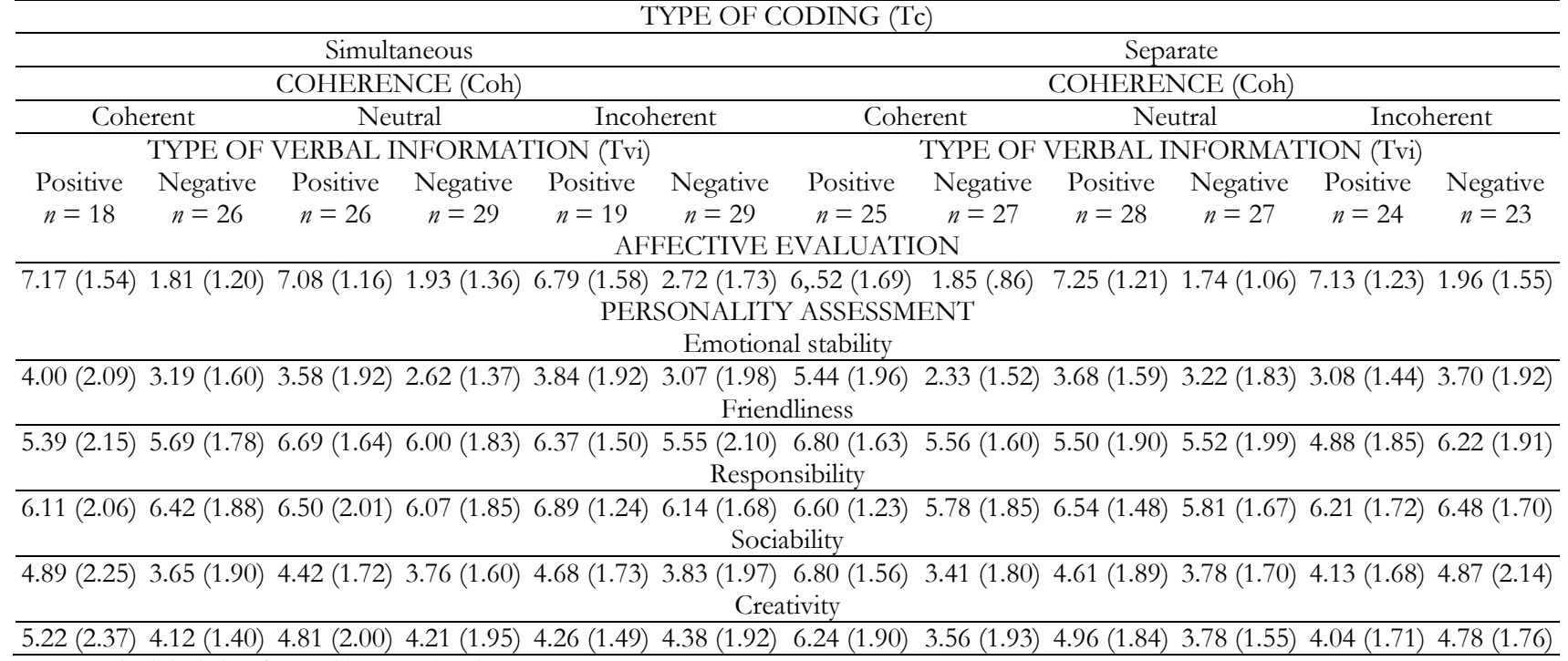

Emotional stability. The analyses showed a significant effect of Tvi $\left(F_{(1,289)}=19.88, p<.001, \eta^{2}=.06, p=.99\right)$, but not of $\operatorname{Coh}\left(F_{(2,289)}=1.82, p=.163, \eta^{2}=.01, p=.38\right)$, or of Tc $\left(F_{(1,288)}=.88, p=.350, \eta^{2}=.00, p=.15\right)$ in the assessment of emotional stability. The differences favoured a positive Tvi $(M=3.94, S D=1.94)$ over a negative one $(M=$ $3.00, S D=1.74)$. The interaction effect was statistically significant between Tiv and $\operatorname{Coh}\left(F_{(2,289)}=6.90, p=.001, \eta^{2}=\right.$ $.05, \mathrm{P}=.92)$, and between Tvi, Coh and Tc $\left(F_{(2,288)}=7.03, p\right.$ $\left.=.001, \eta^{2}=.05, \mathrm{P}=.93\right)$, but not between Tvi and $\mathrm{Tc}\left(F_{(2,}\right.$
289) $\left.=.11, p=.737, \eta^{2}=.00, p=.06\right)$, or between Tc and $\operatorname{Coh}\left(F_{(2,289)}=.398, p=.672, \eta^{2}=.00, p=.11\right)$.

The second-order simple effects analysis (Bonferroni test) revealed that the differences between positive and negative Tvi were significant within the level of the coherent Coh $\left(M_{i-j}=1.957, S E=.364, p<.001\right)$ and within the level of the neutral Coh $\left(M_{i-j}=.706, S E=.336, p=.036\right)$ favourable to the positive Tvi. In turn differences between the coherent and neutral Coh $\left(M_{i-j}=1.092, S E=.363, p=.008\right)$, and between coherent and incoherent $\operatorname{Coh}\left(M_{i-j}=1.257, \mathrm{SE}\right.$ 
$=.383, p=.004)$ were significant solely within the level of the positive Tvi being favourable to the coherent Coh.

The third-order simple effects analysis (Bonferroni test) revealed that the differences between the positive and negative Tvi were significant solely within the level of the coherent Coh and separate Tc $\left(M_{i-j}=3.107, S E=.489, p<\right.$ $.0001)$, being favourable to the positive Tvi. The differences between the coherente and neutral Coh $\left(M_{i-j}=1.761, \mathrm{SE}=\right.$

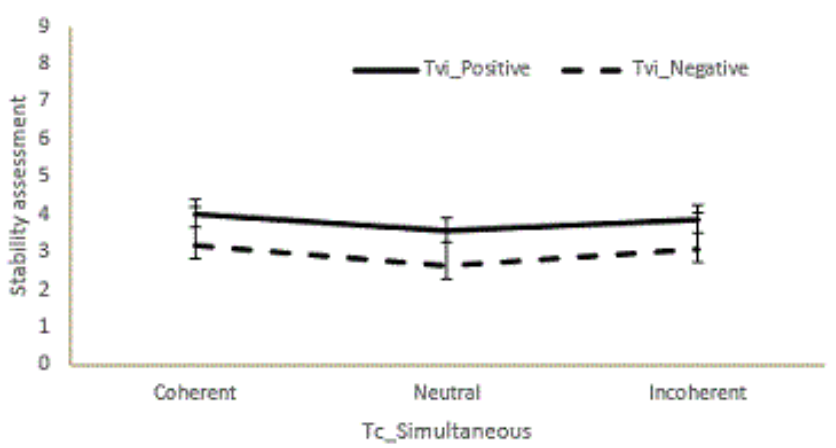

$.484, p=.001)$, and between the coherente and incoherent Coh $\left(M_{i-j}=2.357, S E=.503, p<.0001\right)$ were significant solely within the level of the positive Tvi and separate Tc being favourable to the coherent Coh. In turn the differences between the simultaneous and separate Tc were significant solely within the level of the positive Tvi and coherent Coh $\left(M_{i-j}=1.440, S E=.544, p=.009\right)$ being favourable to the separate Tc (figure 1).

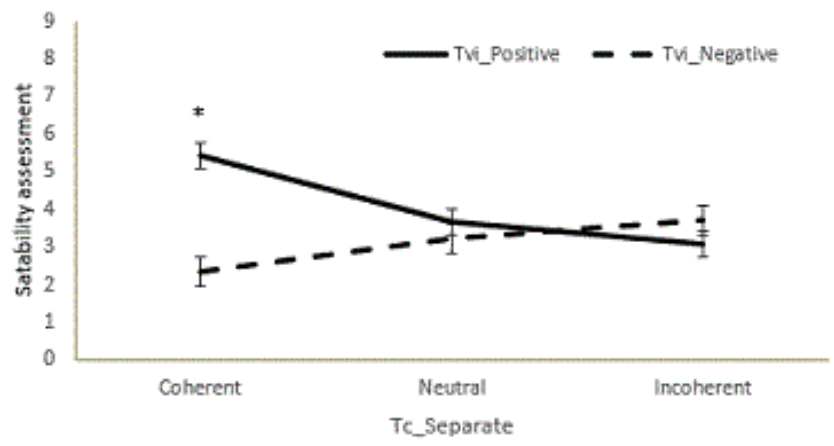

Figure 1. Differences in the assessment of emotional stability in the interaction between Type of Verbal Information (Tvi: positive, negative), Coherence (Coh: coherent, neutral, incoherent), and Type of Coding (Tc: simultaneous, separate). The error bars represent the standard error $\left({ }^{*} p<.001\right)$.

Friendliness. The analyses did not show a significant effect of Tiv $\left(F_{(1,289)}=.72, p=.396, \eta^{2}=.00, p=.14\right)$, or of $\operatorname{Coh}\left(F_{(2,289)}=.23, p=.795, \eta^{2}=.00, p=.09\right)$, or of Tc $\left(F_{(1,}\right.$ $\left.{ }_{288}=.92, p=.339, \eta^{2}=.00, p=.16\right)$ in the assessment of friendliness. The interaction effect was not statistically significant between Tvi and Coh $\left(F_{(2,289)}=1.07, p=.344, \eta^{2}=\right.$ $.01, \mathrm{P}=.24)$, or between Tiv and Tc $\left(F_{(1,289)}=1.06, p=\right.$ $\left..303, \eta^{2}=.00, p=.18\right)$ although it was between Coh and Tc $\left(F_{(2,288)}=4.23, p=.015, \eta^{2}=.03, p=.74\right)$, and also between Tvi, Coh and $\operatorname{Tc}\left(F_{(2,289)}=6.06, p=.003, \eta^{2}=.04, p=.88\right)$.

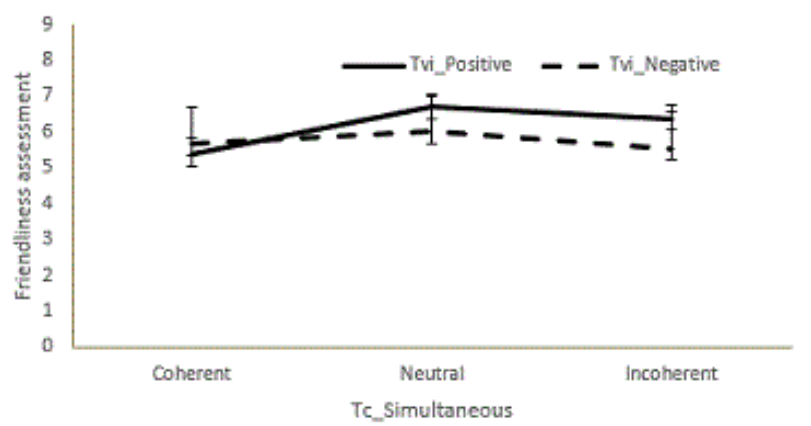

The second-order simple effects analysis (Bonferroni test) revealed that the differences between the simultaneous and separate Tc were significant solely within the level of the neutral Coh $\left(M_{i-j}=.837, S E=.350, p=.017\right)$.

The third-order simple effects analysis (Bonferroni test) revealed that the differences between the positive and negative Tvi were significant within the level of the coherent Coh and separate Tc $\left(M_{i-j}=1.244, S E=.509, p=.015\right)$ being favorable to the positive Tvi, and within the level of incoherent Coh and separate Tc $\left(M_{i-j}=-1.342, S E=.535, p=.013\right)$ being favourable to the negative Tvi (figure 2).

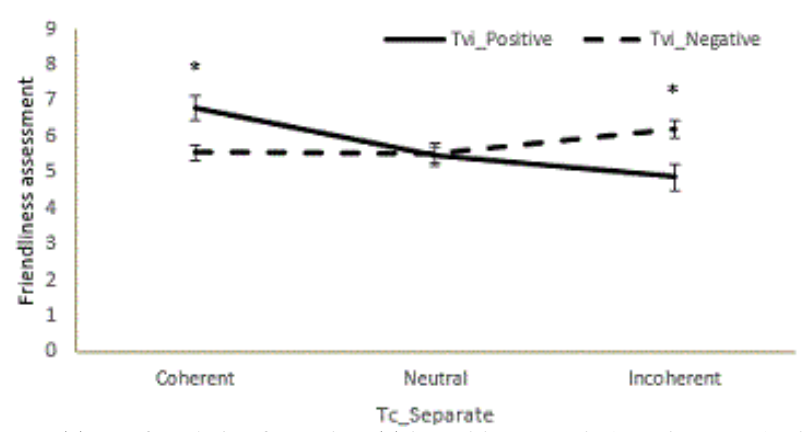

Figure 2. Differences in the assessment of friendliness in the interaction between Type of Verbal Information (Tvi: positive, negative), Coherence (Coh: coherent, neutral, incoherent), and Type of Coding (Tc: simultaneous, separate). The error bars represent the standard error $(* p<.05)$.

Responsibility. The analyses did not show a significant effect of Tvi $\left(F_{(1,289)}=3.21, p=.074, \eta^{2}=.01, p=.43\right)$, or of $\operatorname{Coh}\left(F_{(2,289)}=.437, p=.647, \eta^{2}=.00, \mathrm{P}=.12\right)$, or of Tc $\left(F_{(1,289)}=.361, p=.548, \eta^{2}=.00, p=.09\right)$ in the assessment of responsibility. The interaction effect was not statistically significant between Tvi and $\operatorname{Coh}\left(F_{(1,289)}=.313, p=.731, \eta^{2}\right.$ $=.00, \mathrm{P}=.10)$, or between Tiv and Tc $\left(F_{(1,289)}=.110, p=\right.$ $\left..741, \eta^{2}=.00, \mathrm{P}=.06\right)$, or between Coh and Tc $\left(F_{(1,289)}=\right.$ $\left..019, p=.982, \eta^{2}=.00, \mathrm{P}=.05\right)$, or between Tvi, Coh and Tc $\left(F_{(1,289)}=2.35, p=.097, \eta^{2}=.02, p=.47\right)$.

Sociability. The analyses showed a significant effect of Tvi $\left(F_{(1,289)}=23.86, p<.001, \eta^{2}=.08, p=1.00\right)$, but not of $\operatorname{Coh}\left(F_{(2,289)}=2.26, p=.106, \eta^{2}=.02, p=.46\right)$, or of Tc $\left(F_{(1,}\right.$ 288) $\left.=3.39, p=.067, \eta^{2}=.01, p=.45\right)$ in the assessment of sociability. The differences were in favour of the positive Tiv $(M=4.93, S D=1.98)$, as regards the negative one $(M=$ 
3.86, $S D=1.87)$. The interaction effect was statistically significant between Tvi and Coh $\left(F_{(2,289)}=9.42, p<.001, \eta^{2}=\right.$ $.06, \mathrm{P}=.98)$, and between Tvi, Coh and Tc $\left(F_{(2,288)}=6.19, p\right.$ $\left.=.002, \eta^{2}=.04, p=.89\right)$, but not between Tvi and Tc $\left(F_{(2,}\right.$ $\left.{ }_{289)}=.32, p=.572, \eta^{2}=.00, p=.09\right)$, or between Tc and $\operatorname{Coh}\left(F_{(2,289)}=1.10, p=.333, \eta^{2}=.01, \mathrm{P}=.24\right)$.

The second-order simple effects analysis (Bonferroni test) revealed that the differences between positive and negative Tvi were significant within the level of the coherent $\left(M_{i-j}=2.314, S E=.377, p<.001\right)$ and neutral $\left(M_{i-j}=.747\right.$, $S E=.348, p=.033)$ coh favourable to the positive Tvi. In turn differences between the coherent and neutral $\left(M_{i-j}=\right.$ 1.329, $S E=.376, p=.001)$, and between coherent and incoherent $\left(M_{i-j}=1.440, S E=.398, p=.001\right)$ Coh were significant solely within the level of the positive Tvi being favourable to the coherent Coh.
The third-order simple effects analysis (Bonferroni test) revealed that the differences between the positive and negative Tvi were significant within the level of the coherent Coh and separate Tc $\left(M_{i-j}=3.393, S E=.507, p<.001\right)$, being favourable to the positive Tvi, and within the level of the coherent Coh and simultaneous Tc $\left(M_{i-j}=1.235, \mathrm{SE}=.560\right.$, $p=.028)$ being favourable to the positive Tvi.

The differences between the coherente and neutral Coh $\left(M_{i-j}=2.193, S E=.502, p<.001\right)$, and between the coherente and incoherent $\operatorname{Coh}\left(M_{i-j}=2.675, S E=.522, p<.001\right)$ were significant solely within the level of the positive Tvi and separate Tc being favourable to the coherent Coh. In turn the differences between the simultaneous and separate Tc were significant solely within the level of the positive Tvi and coherent $\operatorname{Coh}\left(M_{i-j}=1.911, S E=.564, p=.001\right)$ being favourable to the separate Tc (see Figure 3).
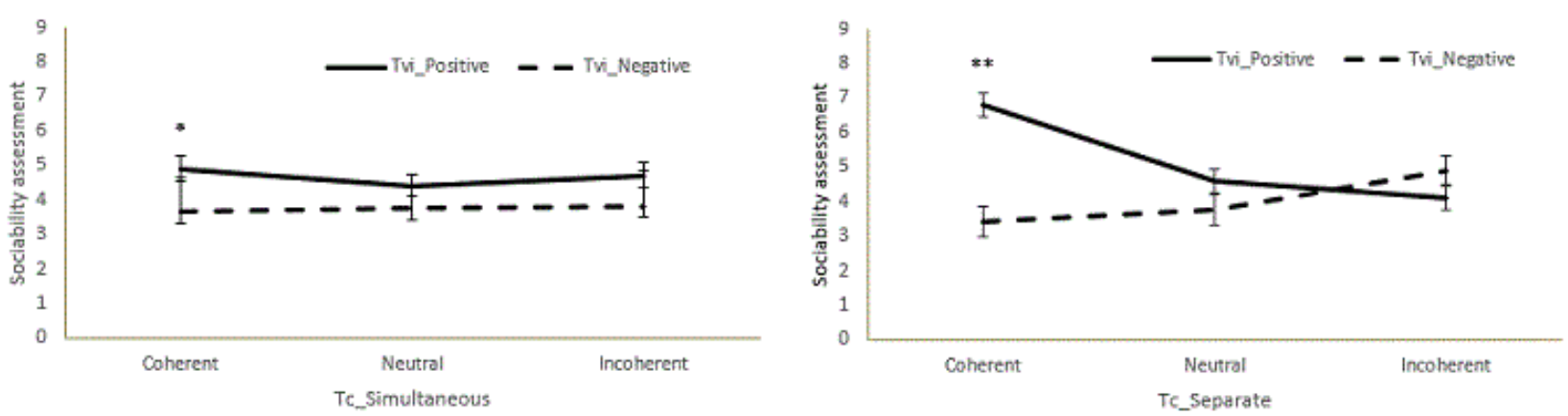

Figure 3. Differences in the assessment of sociability in the interaction between Type of Verbal Information (Tvi: positive, negative), Coherence (Coh: coherent, neutral, incoherent), and Type of Coding (Tc: simultaneous, separate). The error bars represent the standard error $\left({ }^{*} p<.05,{ }^{*} p<.001\right)$.

Creativity. The analyses showed a significant effect of Tvi $\left(F_{(1,289)}=13.66, p<.001, \eta^{2}=.05, p=.96\right)$, but not of Coh $\left(F_{(2,289)}=1.40, p=.247, \eta^{2}=.01, p=.30\right)$, or of Tc $\left(F_{(1,288)}\right.$ $\left.=.08, p=.774, \eta^{2}=.00, p=.06\right)$ in the assessment of creativity. The differences were in favour of the positive Tiv ( $M$ $=4.94, S D=1.99)$ as regards the negative one $(M=4.12$, $S D=1.79)$. The interaction effect was statistically significant between Tvi and Coh $\left(F_{(2,289)}=9.49, p<.001, \eta^{2}=.06, p=\right.$ $.98)$, but not between Tvi and Tc $\left(F_{(1,289)}=1.45, p=.230, \eta^{2}\right.$ $=.01, p=.22)$, or between Tc and $\operatorname{Coh}\left(F_{(2,289)}=.261, p=\right.$ $\left..771, \eta^{2}=.00, p=.09\right)$, or between Tvi, Coh and Tc $\left(F_{(2,288)}\right.$ $\left.=2.12, p=.122, \eta^{2}=.01, p=.43\right)$.

\section{Discussion}

The results obtained enable us to confirm our initial hypotheses and conclude that the coherence between verbal and non-verbal information has a beneficial effect on the formation of impressions when the Tiv is positive and the coding of the verbal and non-verbal information takes place separately. Furthermore, the emotional content of the words and facial expressions used to generate the different conditions of the independent variables did not lead to significant differences in the affective evaluation (stage I) between the levels of the variables Coh and Tc or in their interaction, and only revealed the expected differences between the positive and negative levels of Tvi. This finding is important because it indicates that the differences found did not stem from differences in the participants' affective state, which could have been induced through the verbal information's emotional content, but instead from the coherence between the verbal and non-verbal information.

Our findings here are rooted in the underpinnings reported by Scherer et al. (1977) regarding the importance of the interaction between verbal and non-verbal information in the formation of impressions, and are consistent with those found in other studies, where coherence is established through a series of non-verbal signals that sought coherence or otherwise with verbal information (Weisbuch et al., 2010). These authors, however, used a molar perspective and a methodology different to the one considered here (videos vs. photos). This research has imposed proper laboratory control to prompt information coherence through specific stimuli (facial expressions - verbal descriptors).

Proof is forthcoming for the first time of the modulating effect emotional coherence has on personality traits such as emotional stability, friendliness and sociability, where modulating variables such as the type of emotion and the moment of coding are significant and have a clear theoretical value that is applicable to natural contexts. Nevertheless, in- 
coherence has not been shown to have any important compromising effects on the formation of impressions, contrary to what was expected in the light of other studies (Argyle et al., 1971; Heinrich \& Borkenau, 1998). These studies made inferences about the falseness perceived, while this study valued more stable aspects such as personality. Coherence may be perceived as being more stable over time, and is therefore more readily associated with personality, whereas incoherence is attributed a more circumstantial causality (e.g., the person is upset, something's wrong, they're trying to bide something, they're not like that).

\section{Theoretical implications}

Given that the verbal context has a markedly dimensional nature (positive, negative), the effects found are more consistent on dimensions such as emotional stability, friendliness and sociability. Within the implicit theories -set of relatively consistent beliefs that are used to predict a certain number of phenomena (Estrada et al., 2007)-, the aforementioned aspects would allow contending that those people who have undergone certain life experiences tend to have personality traits that are typical of those situations. Nevertheless, one might expect that the level of coherence between verbal and non-verbal information will be determined by the extent to which the relationship between verbal and non-verbal information may be attributed to the dimensions of personality analysed. The words used in this research to constitute the positive Tvi (family, excitement, adventure, sex, and optimism) would be extremely coherent with the expression of happiness; however, the words used here to constitute the negative Tvi (abuse, poverty, horror, nightmare, and depression) might be less coherent in their relationship with the expression of sadness, as words such as nightmare and horror are more coherent with expressions such as fear. This might explain why the effect of coherence between the negative Tvi and the expression of sadness has not proven to be significant.

\section{Practical implications}

The inferences made on personality enable us to predict another person's behaviour (Stecher \& Counts, 2008), and therefore condition the decisions we make in different situations, such as at work (will this employee perform well?), on a personal basis (will they be a suitable partner?) or in the courtroom (are they guilty?). When making a decision that involves another person, the information that is consistent with the personality that we attribute to them will be recovered more easily (Stecher \& Counts, 2008: Ferreira, García-Marqués, Hamilton, \& Ramos, 2012). For example, if we attribute low levels of responsibility and sociability to a certain individual, the information that reaches us regarding their behaviour that is consistent with these traits (e.g., he sometimes forgets to collect his children from school, he hardly ever said hello to me and he always seemed distracted) will have greater salience, and will therefore be coded, stored and recovered more effectively than any information that is inconsistent with the inference made (e.g., he always behaved well toward me and he seemed to be very affectionate toward his children). The data found in this research highlight the importance within courtroom proceedings of variables such as the moment of presenting verbal and nonverbal information and the coherence between that information in the impression that the defendant could give to the judge and jury, in view of their potentially modulating effect on the court's decisions (verdict).

Furthermore, the effect of information coherence through the formation of impressions has proven to be relevant and positive in negotiations (Kulik et al., 2014), and in clinical areas such as psychotherapy (Battles \& Berman, 2012). It would acquire particular importance within a hospital context, as the medical staff's ability to be coherent in the information provided to patients will have a major impact on how each one actually perceives the staff, reducing their levels of anxiety in a way that will be extremely beneficial to their treatment and recovery.

\section{Limitations and future research}

The limitations of this research are centred on the use of a single stimulus for generating three kinds of facial expressions. The reason for this is that the online experimental task needed to be undertaken by considering that it might decrease the participants' motivation and concentration if it were overly long, because they were not subject to the researcher's "supervision", and a laboratory context might have had an uncontrolled impact on the results. Accordingly, the brevity of the task was a necessary requirement for controlling the variables. On the other hand, more direct questionnaires for measuring the participants' affective state were not administered because they would have led to a considerable time lapse between stage I and stage II, which might have compromised the efficacy of the experimental procedure. Hence the reason for adopting an indirect measure through the affective evaluation used in stage I. Future research should consider the joint effect of the perceiver's affective state on information coherence, as well as analyse variables such as age, gender and culture (e.g., Krys et al., 2013).

\section{References}

Abrosoft (2010). FantaMorph (Version 5.0) [Computer software].

Albright, L., Kenny, D., \& Malloy, T. (1988). Consensus in personality judgments at zero acquaintance. Journal of Personality and Social Psychology, 55(3), 387-395. doi: 10.1037/0022-3514.55.3.387
Ambady, N., Bernieri, F. J., \& Richeson, J. A. (2000). Toward a histology of social behavior: Judgmental accuracy from thin slices of the behavioral stream. Advances in Experimental Social Psychology, 32, 201-271. doi: 10.1016/s0065-2601(00)80006-4. 
Argyle, M., Alkema, F., \& Gilmour, R. (1971). The communication of friendly and hostile attitudes by verbal and nonverbal signals. European Journal of Social Psychology, 1(3), 385-402. doi: 10.1002/ejsp.2420010307

Aviezer, H., Hassin, R., Ryan, J., Grady, C., Susskind, J., Anderson, A., Moscovitch, M., \& Bentin, S. (2008). Angry, disgusted or afraid? Studies on the malleability of emotion perception. Psychological Science, 19(7), 724732. doi: $10.1111 /$ j.1467-9280.2008.02148.x

Bargh, J. A. (2006). What have we been priming all these years? On the development, mechanisms, and ecology of nonconscious social behavior. European Journal of Social Psychology, 36(2), 147-168. doi: 10.1002/ejsp.336.

Battles, M. B., \& Berman, J. S (2012). The impact of conversational acknowledgers on perceptions of psychotherapists. Psychotherapy Research, 22(6), 648-655. doi: 10.1080/10503307.2012.699476

Berry, D. S. (1990). Taking people at face value: Evidence for the kernel of truth hypothesis. Social Cognition, 8(4), 343-361. doi: 10.1521/soco.1990.8.4.343

Bond, C., Berry, D., \& Omar, A. (1994). The kernel of truth in judgments of deceptiveness. Basic and Applied Social Psychology, 15, 523-534. doi: 10.1207/s15324834basp1504_8

Bruner, J. S., \& Tagiuri, R. (1954). The perception of people. In G. Lindsay (Ed.), Handbook of social psychology (Vol. 2). Cambridge, MA: AddisonWesley.

Costa, P. T., \& McCrae, R. R. (1985). The NEO Personality Inventory Manual. Odessa, FL: Psychological Assessment Resources.

Costa, P. T., \& McCrae, R. R. (1992). Revised NEO Personality Inventory (NEO$P I-R)$ and NEO Five-Factor Inventory (NEO-FFI) professional manual. Odessa, FL: Psychological Assessment Resources.

Estrada, C., Oyarzún, M., \& Yzerbyt, V (2007). Teorías implícitas y esencialismo psicológico: Herramientas conceptuales para el estudio de las relaciones entre y dentro de los grupos. Psykhe, 16(1), 111-121.

Fenske, M. J., \& Eastwood, J. D. (2003). Modulation of focused attention by faces expressing emotion: Evidence from flanker tasks. Emotion, 3(4), 327-341. doi: 10.1037/1528-3542.3.4.327

Ferreira, M. B., García-Marqués, L., Hamilton, D., \& Ramos, T. (2012). On the relation between spontaneous trait inferences and intentional inferences: An inference monitoring hypothesis. Journal of Experimental Social Psychology, 48(1), 1-12. doi: 10.1016/j.jesp.2011.06.013.

Fox, E., Russo, R., Bowles, R. J., \& Dutton, K. (2001). Do threatening stimuli draw or hold visual attention in sub-clinical anxiety? Journal of Experimental Psychology: General, 130(4), 681-700. doi: 10.1037/00963445.130.4.681

Hareli, S., \& Weiner, B. (2002). Social emotion and personality inferences: A scaffold for a new direction in the study of achievement motivation. Educational Psychologist, 37(3), 183-193. doi: 10.1207/S15326985EP37034

Hehman, E., Leitner, J. B., Deegan, M. P., \& Gaertner, S. L. (2013). Facial structure is indicative of explicit support for prejudicial beliefs. Psychological Science, 24(3), 289-296. doi: 10.1177/0956797612451467

Heinrich, C. U., \& Borkenau, P. (1998). Deception and deception detection: The role of cross-modal inconsistency. Journal of Personality, 66(5), 687712. doi: 10.1111/1467-6494.00029

Hodsoll, S., Viding, E., \& Lavie, N. (2011). Attentional Capture by Irrelevant Emotional Distractor Faces. Emotion, 11(2), 346-353. doi: $10.1037 / \mathrm{a} 0022771$

Krys, K., Hansen, K., Xing, C., Szarota, P., \& Yang, M. (2013). Do only fools smile at strangers? Cultural differences in social perception of intelligence of smiling individuals. Journal of Cross-Cultural Psychology, 45(2), 314-321. doi: 10.1177/0022022113513922

Kulik, C. T., Olekalns, M., \& Swain, E. T. (2014). Does consistency pay? The effects of information sequence and content on women's negotiation outcomes. ACAD MANAGE PROC, 11675. doi: 10.5465/AMBPP.2014.97

LaBar, K. S., \& Cabeza, R. (2006). Cognitive neuroscience of emotional memory. Nature Reviews Neuroscience, 7(1), 54-64. doi:10.1038/nrn1825
Lamy, D., Amunts, L., \& Bar-Haim, Y. (2008). Emotional priming of popout in visual search. Emotion, 8(2), 151-161. doi: 10.1037/15283542.8.2.151

Lerner, J. S., Li, Y., Valdesolo, P., \& Kassam, K. S. (2015). Emotion and decision making. Annual Review of Psychology, 66, 33.1-33.25. doi: 0.1146/annurev-psych-010213-115043

Lieberman, M. D., Jarcho, J. M., \& Obayashi, J. (2005). Attributional inference across cultures: Similar automatic attributions and different controlled corrections. Personality and Social Psychology Bulletin, 31(10), 1-14. doi: $10.1177 / 0146167204274094$

Matsumoto, D., \& Hwang, H (2010). Judging faces in context. Social and Personality Psychology Compass, 4(6), 393-402. doi: 10.1111/j.17519004.2010.00271.x

Mogg, K., \& Bradley, B. P. (1999). Orienting of attention to threatening facial expressions presented under conditions of restricted awareness. Cognition \& Emotion, 13(6), 713-740. doi: 10.1080/026999399379050

Niedenthal, P. M., \& Setterlund, M. B. (1994). Emotion congruence in perception. Personality and Social Psychology Bulletin, 20(4), 401-410. doi: 10.1177/0146167294204007

Ohman, A., Lundqvist, D., \& Esteves, F. (2001). The face in the crowd revisited: A threat advantage with schematic stimuli. Journal of Personality and Social Psychology, 80(3), 381-396. doi: 10.1037/0022-3514.80.3.381

Ramos, T., García-Marqués, L., Hamilton, Ferreira, D. L., \& Van Acker, K. V. (2012). What I infer depends on who you are: The influence of stereotypes on trait and situational spontaneous inferences. Journal of Experimental Social Psychology, 48, 1247-1256. doi: 10.1016/i.jesp.2012.05.009.

Redondo, J., Fraga, I., Comesaña, M., \& Perea, M. (2005). Estudio normativo de 478 palabras españolas. Psicológica, 26, 317-326.

Reeck, C. (2015). Interactions between attention and emotion. Brain Mapping, 3, 269-274. doi: 10.3389/fnins.2012.00139

Sandal, G. M., Bye, H.H., \& Pallesen, S. (2012). Personality trait inferences of Turkish immigrant and neutral targets: an experimental study. Scand J Psychol, 53(6), 528-33. doi: 10.1111/sjop.12016.

Scherer, K. R., Scherer, U., Hall, J. A., \& Rosenthal, R. (1977). Differential attribution of personality based on multichannel presentation of verbal and nonverbal cues. Psychological Research, 39(3), 221-247. doi: 10.1007/BF00309288

Schneider, D. J., Hastorf, A. H., \& Ellsworth, P. C. (1979). Person perception. Reading, MA: Addison-Wesley.

Stecher, K., \& Counts, S. (2008). Spontaneous Inference of Personality Traits and Effects on Memory for Online Profiles. En: Proc. Int. AAAI Conference on Weblogs and Social Media (ICWSM).

Stein, T., Zwickel, J., Ritter, J., Kitzmantel, M., \& Schneider, W. X. (2009). The effect of fearful faces on the attentional blink is task dependent. Psychonomic Bulletin \& Review, 16(1), 104-109. doi: 10.3758/PBR.16.1.104

Tottenham, N., Tanaka, J. W., Leon, A. C., McCarry, T., Nurse, M., Hare, T. A., Marcus, D. J., Westerlund, A., Casey, B. J., \& Nelson, C. (2009). The NimStim set of facial expressions: judgments from untrained research participants. Psychiatry Research, 168(3), 242-249. doi: 10.1016/j.psychres.2008.05.006

Van den Stock, J., Grezes, J., \& de Gelder, B. (2008). Human and animal sounds influence recognition of body language. Brain Research, 1242, 185-190. doi: 10.1016/j.brainres.2008.05.040

Walker-Andrews, A. S. (2008). Intermodal emotional processes in infancy. In M. Lewis, J. M. Haviland-Jones, \& L. F. Barrett (Eds.), Handbook of emotions (pp. 364-375). New York: Guilford

Weisbuch, M., Ambady, N., Clarke, A. L., \& Achor, S. (2010). On being consistent: The role of verbal-Nonverbal consistency in first impressions. Basic and Applied Social Psychology, 32(3), 261-268. doi: 10.1080/01973533.2010.495659

Wieser, M. J., \& Brosch, T. (2012). Faces in context: a review and systematization of contextual influences on affective face processing. Frontiers in Psychology, 3, 471. doi: 10.3389/fpsyg.2012.00471 